\title{
Um estudo do rendimento do veneno de cobras corais brasileiras e seu uso na avaliação do soro antielapídico
}

\author{
A study on venom yield of Brazilian coralsnakes and its use in the evaluation of \\ antielapidic serum
}

\author{
Anderson Vieira Carvalho' ${ }^{1}$, Caroline Ferreira David ${ }^{1}$, Anita de Moura Pessoa ${ }^{2}$, Nelson Jorge da Silva Jr. ${ }^{3}$ \\ ${ }^{1}$ Graduandos da Faculdade de Medicina da Pontifícia Universidade Católica de Goiás (PUC Goiás), Goiânia, GO; ${ }^{2}$ Mestre em Ciências Ambientais e Saúde pela PUC \\ Goiás, Goiânia, GO; ${ }^{3}$ Doutor em Zoologia pela Brigham Young University, Professor titular da PUC Goiás, Coordenador do Programa de Pós-Graduação em Ciências
} Ambientais e Saúde da PUC Goiás, Goiânia, GO.

\section{RESUMO}

Objetivos: Investigar a correlação entre quantidade de veneno produzido por uma cobra coral verdadeira e o tamanho da mesma, e avaliar a produção e o uso do soro antielapídico, levando em conta tamanho, capacidade inoculatória e variabilidade de espécies dessas cobras nas diversas regiões do Brasil.

Métodos: Para avaliação da diversidade e distribuição geográfica, foi realizada pesquisa bibliográfica e eletrônica no site oficial da Sociedade Brasileira de Herpetologia. Para obtenção de dados sobre epidemiologia dos acidentes elapídicos, foi pesquisado o Sistema de Informação de Agravos a Notificação do Ministério da Saúde. Dados de quantidade de veneno e tamanho das cobras das quais o mesmo foi extraído foram obtidos em trabalho de campo realizado entre os anos de 1986 e 2010, que estavam armazenadas no banco de venenos do Centro de Estudos e Pesquisas Biológicas da Pontifícia Universidade Católica de Goiás.

Resultados: A maior diversidade de espécies de cobras corais verdadeiras está na região Norte e a maior casuística de acidentes elapídicos na região Nordeste. A análise de regressão linear mostrou forte correlação entre tamanho corporal e quantidade de veneno extraído. A maioria das espécies de cobras corais apresenta tamanho pequeno ou médio. Foi identificada uma diversidade de 35 táxons de cobras corais no Brasil, enquanto o soro antielapídico em uso no País é produzido a partir de três espécies.

Conclusões: Devido ao porte reduzido, que resulta em baixa capacidade inoculatória, a recomendação de altas doses de soro antielapídico na ocorrência de acidentes com cobras corais deveria ser revista. Entretanto, a especificidade do veneno de cada espécie gera preocupação sobre a eficácia do soro antielapídico produzido a partir de um número reduzido de espécies de cobras corais.

DESCRITORES: BIODIVERSIDADE; ELAPIDAE; IMUNIZAÇÃO PASSIVA.

\section{ABSTRACT}

Aims: To investigate the correlation between the amount of venom produced by a true coral snake and its size, and to evaluate the production and use of antielapidic serum, taking into account size, innoculatory power, and variability of these species in different regions of Brazil.

Methods: To assess the diversity and geographic distribution we conducted a bibliographic review and electronic search in the official site of the Brazilian Herpetological Society. Diseases Report Information System of the Ministry of Health was consulted to obtain data on the epidemiology of elapidic accidents. Data on amount of extracted venom and size of the snakes were obtained from fieldwork conducted between 1986 and 2010, which data were stored in the venom database of the Centre for Studies and Biological Research of the Catholic University of Goiás.

Results: The greatest diversity of species of coral snakes are in the Northern region and the largest sample of Micrurus accidents in the Northeast region. Linear regression analysis showed a strong correlation between body size and amount of venom extracted. Most species of coral snake have small or medium size. A diversity of 35 taxa of coral snakes in Brazil has been identified, while the antielapidic serum in use in this country is produced from three species.

Conclusions: Due to the small size, which results in low innoculatory capacity, recommending high doses of antielapidic serum in accidents with coral snakes should be revised. However, the specificity of the venom of each species raises concerns about the effectiveness of antielapidic serum produced from a small number of species of coral snakes.

KEY WORDS: BIODIVERSITY; ELAPIDAE; PASSIVE IMMUNIZATION. 


\section{INTRODUÇÃO}

$\mathrm{Na}$ América do Sul, as cobras corais estão representadas pelos gêneros Micrurus e Leptomicrurus e, embora raros, os envenenamentos em humanos são sempre considerados graves. Atualmente são conhecidas para o Brasil 35 espécies de Micrurus e três de Leptomicrurus, mas pouco se sabe sobre a história natural desse último grupo. A partir dessa diversidade, deve-se considerar também a possível variabilidade de toxinas entre espécies, sua implicação nos acidentes com humanos e sua conduta terapêutica. ${ }^{1-4}$

Experimentalmente, os venenos dessas serpentes são conhecidos por serem neurotóxicos, miotóxicos, hemorrágicos, e causarem alterações cardiovasculares. Entretanto, em acidentes humanos, somente os efeitos neurotóxicos e miotóxicos foram observados. ${ }^{2-6} \mathrm{~A}$ constituição química do veneno de uma espécie, e consequentemente as ações biológicas, podem estar representados em indivíduos de uma mesma população ou em indivíduos de populações diferentes. Por outro lado, uma mesma espécie pode expressar diferentes concentrações desses componentes, e assim essas variações podem acarretar diferentes sinais e sintomas em pacientes acidentados. ${ }^{7}$

Oficialmente, o soro antielapídico (SAE) no Brasil é fabricado pelo Instituto Butantan (IB), em São Paulo/ SP, pelo Instituto Vital Brazil (IVB), em Niterói/RJ e pela Fundação Ezequiel Dias (FUNED), em Belo Horizonte/MG, sendo produzido a partir dos venenos de três espécies do gênero Micrurus: $M$. corallinus, $M$. frontalis e M. lemniscatus quando há disponibilidade (pool de imunização). Essas espécies são consideradas comuns em regiões populosas, como a região Sudeste, o que facilita a coleta de espécimes para a obtenção do veneno. Entretanto, estudos realizados com o veneno de outras espécies mostram diferentes toxinas na sua composição, o que pode diminuir a eficácia do SAE. ${ }^{8,9}$

Se tomada como referência, a bula do SAE do Instituto Butantan indica que cada ampola de $10 \mathrm{~mL}$ é uma solução injetável da fração $\mathrm{F}(\mathrm{ab})_{2}$ de imunoglobulinas específicas da classe IgG, purificadas de plasma hiperimunizado de equinos com um pool de venenos de serpentes do gênero Micrurus. Especificamente, os testes laboratoriais indicam que cada ampola de $10 \mathrm{~mL}$ é capaz de neutralizar, no mínimo, $15 \mathrm{mg}$ de veneno de Micrurus. ${ }^{10}$

Em 1978, Bolaños et al. ${ }^{11}$ realizaram estudos experimentais sugerindo a possibilidade de produção de um antiveneno para as Américas, onde se verificou que o antiveneno produzido no Brasil não era capaz de neutralizar os efeitos do veneno de algumas espécies brasileiras, abrindo assim a discussão sobre a adequação dos venenos selecionados para compor o pool de imunização.

A importância da discussão pode ser exemplificada em um estudo mais recente de neutralização cruzada realizado por Tanaka et al. ${ }^{11}$ que utilizou diversas técnicas. Nesse estudo os autores compararam a eficácia do SAE produzido pelo Instituto Butantan contra o veneno de oito espécies de Micrurus do Brasil. Os resultados demonstraram a impossibilidade de reconhecimento de uma grande quantidade de componentes dos venenos analisados. ${ }^{12}$

$\mathrm{O}$ avanço agrícola em regiões como Amazônia e Nordeste, aliado à alta diversidade de espécies de cobras corais, pode, talvez em médio ou longo prazo, contribuir para o aumento da letalidade, desde que a falta de conhecimento biológico e toxinológico sobre essas espécies pode causar erros na soroterapia. ${ }^{13}$

O objetivo deste estudo foi avaliar a produção e uso do SAE em relação à variabilidade biológica de cobras corais brasileiras, incluindo o tamanho e a capacidade inoculatória dessas serpentes. Para tanto, buscamos relacionar a quantidade de veneno extraído com o tamanho corporal de algumas espécies.

\section{MÉTODOS}

\section{Diversidade das espécies}

A diversidade de espécies de Micrurus no Brasil foi obtida com base nos dados apresentados por Bérnils e Costa, ${ }^{1}$ Roze, ${ }^{14}$ Campbell e Lamar ${ }^{15}$ e Pires et al. ${ }^{4}$ Os dados obtidos foram utilizados para a confecção de um mapa distribucional, destacando a diversidade de espécies por região geográfica do Brasil. Nesse sentido, levaram-se em consideração somente as informações na modalidade presença-ausência de um táxon em cada estado e, consequentemente, extrapolado para a região.

\section{Dados epidemiológicos oficiais}

Os dados epidemiológicos oficiais dos acidentes elapídicos foram obtidos a partir do sistema eletrônico do Sistema de Informação de Agravos de Notificação (SINAN) do Ministério da Saúde, num recorte temporal de cinco anos (2007-2011).

\section{Coleta das amostras}

As amostras de veneno foram obtidas através da massagem manual das glândulas de veneno de espécimes de Micrurus, realizadas por um dos autores (NJS), entre 1986 e 2010, em localidades do Brasil, Colômbia 
e Paraguai, com os dados mantidos no banco de venenos do Centro de Estudos e Pesquisas Biológicas (CEPB) da Pontifícia Universidade Católica de Goiás (PUC Goiás) e expressas em miligramas (mg) de peso seco. A biometria dos espécimes foi obtida quando das extrações manuais e os dados mantidos nesse banco de dados.

\section{Análise dos dados}

Os dados referentes à quantidade de veneno e ao tamanho corporal das espécies estudadas foi apresentada com base em estatística descritiva considerando os valores mínimo, máximo e média. Para testar se havia correlação entre a variável dependente (quantidade de veneno) e a independente (tamanho corporal), foi realizada regressão linear simples, onde a inclinação da reta pode variar entre $-1 \mathrm{a}+1$ e mostra o percentual da variância de uma das variáveis que pode ser explicado a partir do valor da outra (coeficiente de determinação). O coeficiente de correlação é dado pelo valor de $\mathbf{r}$ e expressa a força do relacionamento linear entre valores pareados na amostra, já o coeficiente de determinação, representado pelo valor de $\mathbf{R}^{2}$ indica a proporção (ou porcentagem) da variação de Y que é explicada pela regressão, ou quanto da variação na variável dependente $\mathrm{Y}$ está sendo explicada pela variável independente $\mathrm{X}$, enquanto $\mathbf{p}$ representa a probabilidade da correlação ter ocorrido ao acaso e seu valor aceitável para correlação estatisticamente significativa foi de $\mathrm{p} \leq 0,05$ (95\%).

\section{RESULTADOS}

Segundo as fontes bibliográficas descritas na metodologia, são registradas para o Brasil 35 espécies e subespécies (táxons) de Micrurus. A região Norte é a que apresenta maior diversidade de cobras corais (24 táxons), seguida das regiões Centro-Oeste (11 táxons), Nordeste (nove táxons), Sul (seis táxons) e Sudeste (cinco táxons) (Figura 1).

De acordo com as informações disponibilizadas pelo SINAN, entre 2007 e 2011 foram notificados 1.003 acidentes humanos elapídicos (causados por Micrurus). Desses, 521 (52\%) foram registrados na região Nordeste, $213(21 \%)$ na região Sudeste, 123 (12\%) na região Norte, 83 (8\%) na região Centro-Oeste e 63 (7\%), na região Sul. ${ }^{16}$ Não existem dados oficiais sobre o uso do SAE no Brasil, devido ao reduzido número de estudos regionais ou estaduais, sendo assim, pouco representativos em termos de recortes temporais.

As amostras de veneno que foram extraídas entre os anos de 1986 e 2010, e estavam armazenadas no banco

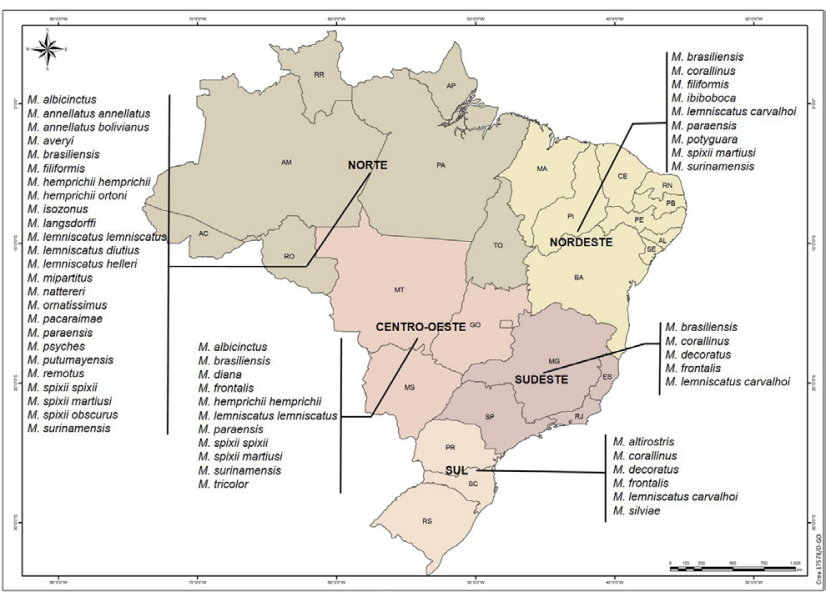

Figura 1. Distribuição regional das Espécies de Micrurus no Brasil (Com base em Bérnils e Costa ${ }^{1}$ Roze, ${ }^{14}$ Campbell e Lamar $^{15} \mathrm{e}$ Pires et al. $\left.{ }^{4}\right)$.

Veja esta imagem em maior definição: http://revistaseletronicas. pucrs.br/ojs/index.php/scientiamedica/article/view/16119/11482

de venenos do CEPB da PUC Goiás, representavam 277 amostras de 15 táxons de Micrurus de 20 localidades, entre Brasil, Colômbia e Paraguai (Tabela 1).

Ao relacionarmos o comprimento do corpo da serpente com a quantidade de veneno extraído, podemos observar que a menor média de quantidade de veneno extraída foi de Micrurus decoratus, com 8,76 mg, que apresentou comprimento corporal médio de $602,59 \mathrm{~mm}$. Já a maior média foi de Micrurus surinamensis, com 40,47 mg de veneno extraído e média do comprimento do corpo de 939,51 mm (Figura 2).

A correlação entre a média do comprimento corporal e a média da quantidade de veneno extraído foi testada através de uma regressão linear, mostrando-se positiva e estatisticamente significativa. Um coeficiente de correlação $(r=0,83)$, que mede a força entre as variáveis estudadas, explicou $88 \%$ da correlação $(r=0,83 ; p \leq 0,05)$ (Figura 3).

Quanto à correlação entre as variáveis quantidade de veneno e tamanho, foi possível separar as espécies em três grupos: 1) espécies que apresentaram correlação positiva e não significativa ( $r>0$ e $p \geq 0,05)$; 2) espécies que apresentaram correlação positiva e significativa $(\mathrm{r}>0$ e $\mathrm{p} \leq 0,05)$; e 3$)$ espécies que apresentaram correlação negativa e não significativa $(r<0$ e $p \geq 0,05)$.

Sete espécies apresentaram correlação positiva e não significativa (M. albicinctus, $M$. altirostris, $M$. lemniscatus helleri, M. ibiboboca, M. brasiliensis, $M$. averyi e $M$. decoratus) o que é explicado pela distribuição não normal das amostras ao longo da reta, refletindo diretamente e aumentando a variação não explicada pelo modelo (Tabela 2). 
Tabela 1. Quantidade de extrações de veneno por espécie relacionando o intervalo de variação do comprimento do corpo $(\mathrm{mm})$ e a quantidade de veneno $(\mathrm{mg})$ obtida nas extrações

\begin{tabular}{|lccccc}
\multicolumn{1}{c}{ Espécie } & N & \multicolumn{2}{c}{ Comprimento do Corpo $(\mathbf{m m})$} & \multicolumn{2}{c}{ Quantidade de Veneno $(\mathbf{m g})$} \\
\cline { 3 - 6 } & & Mínimo-Máximo & Média & Mínimo-Máximo & Média \\
\hline Micrurus albicinctus & 5 & $550,04-675,18$ & 609,01 & $8,04-10,81$ & 9,63 \\
\hline Micrurus altirostris & 20 & $679,25-865.23$ & 753,3 & $15,88-19,66$ & 17,76 \\
\hline Micrurus averyi & 3 & $566,42-676,41$ & 619,85 & $12,44-13,13$ & 12,88 \\
\hline Micrurus brasiliensis & 8 & $675,89-766,89$ & 722,76 & $15,45-18,12$ & 16,87 \\
\hline Micrurus corallinus & 13 & $541,24-732,16$ & 651,64 & $15,07-17,64$ & 15,47 \\
\hline Micrurus decoratus & 3 & $350,14-403,18$ & 602,59 & $8,06-10,06$ & 8,76 \\
\hline Micrurus frontalis & 130 & $544,13-1.037,22$ & 822,5 & $11,76-32,54$ & 18,92 \\
\hline Micrurus hemprichii & 7 & $604,33-748,66$ & 693,05 & $15,26-18,4$ & 16,58 \\
\hline Micrurus ibiboboca & 6 & $696,48-843,54$ & 739,76 & $15,98-18,44$ & 17,08 \\
\hline Micrurus I. carvalhoi & 21 & $587,18-876,54$ & 757,54 & $17,09-25,62$ & 20,09 \\
\hline Micrurus I. helleri & 10 & $806,57-924,15$ & 861,02 & $21,18-24,13$ & 22,7 \\
\hline Micrurus I. lemniscatus & 9 & $669,45-833,71$ & 779,92 & $17,24-24,18$ & 19,79 \\
\hline Micrurus s. obscurus & 14 & $723,67-956,67$ & 837,62 & $17,78-32,23$ & 23,59 \\
\hline Micrurus s. spixii & 15 & $712,44-906,18$ & 802,64 & $16,27-28,45$ & 22,54 \\
\hline Micrurus surinamensis & 13 & $865,28-1.008,44$ & 939,51 & $34,08-52,67$ & 40,47 \\
\hline Total & 277 & $350,14-1.037,22$ & 746,18 & $8,04-52,67$ & 18,87 \\
\hline
\end{tabular}



Figura 2. Comparação, por espécie, entre comprimento total do corpo (coluna) e média da quantidade de veneno extraído (linha)

Figura 3. Regressão linear entre a quantidade de veneno extraída e o comprimento do corpo das espécies de Micrurus

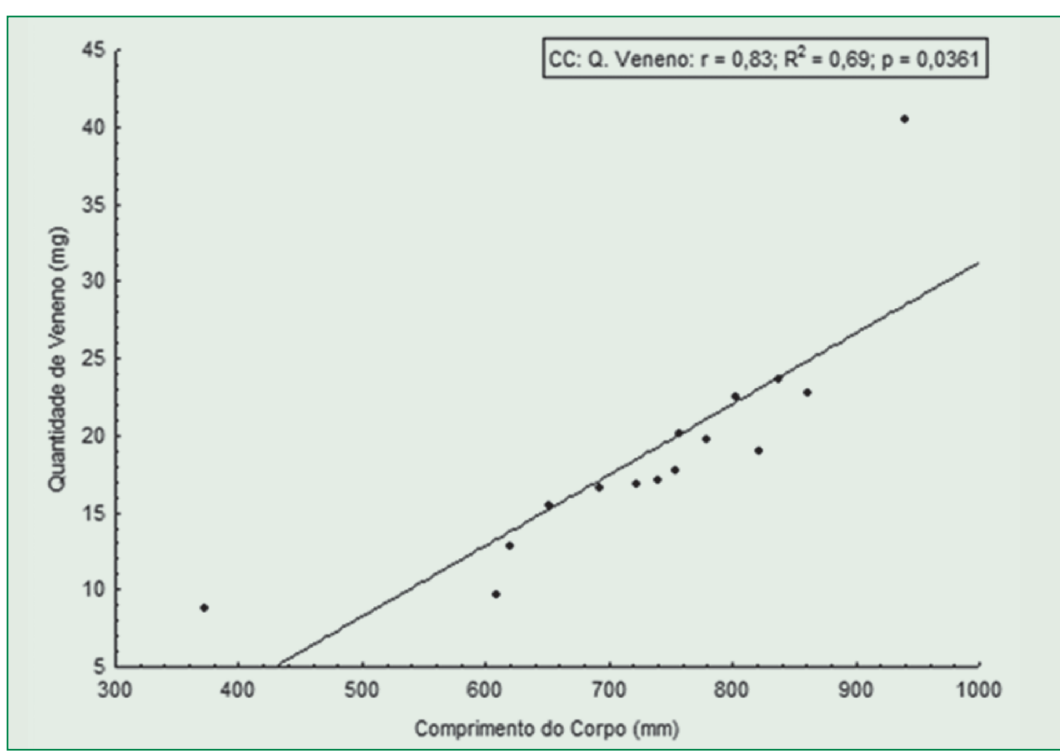


Tabela 2. Coeficiente de correlação linear entre a quantidade de veneno extraído por espécie de Micrurus e seu comprimento corporal, e força da correlação entre as variáveis

\begin{tabular}{lccccc}
\multicolumn{1}{c}{ Espécie } & $\mathbf{N}^{\circ}$ de amostras & $\mathbf{r}$ & $\mathbf{p}$ & $\mathbf{R}^{\mathbf{2}}$ & Força da correlação* \\
\hline M. albicinctus & 5 & 0,0628 & 0,9201 & 0,0039 & Bem fraca \\
\hline M. altirostris & 20 & 0,149 & 0,5307 & 0,0222 & Bem fraca \\
\hline M. averyi & 3 & 0,8868 & 0,3059 & 0,7864 & Forte \\
\hline M. brasiliensis & 8 & 0,6598 & 0,0750 & 0,4353 & Moderada \\
\hline M. corallinus & 13 & 0,5736 & 0,0404 & 0,3291 & Moderada \\
\hline M. decoratus & 3 & 0,9655 & 0,1678 & 0,9321 & Muito forte \\
\hline M. frontalis & 130 & 0,6276 & 0,0000 & 0,3939 & Moderada \\
\hline M. hemprichii & 7 & $-0,295$ & 0,5208 & 0,087 & Fraca \\
\hline M. ibiboboca & 6 & 0,5709 & 0,2376 & 0,3259 & Moderada \\
\hline M. lemniscatus carvalhoi & 21 & 0,6653 & 0,0010 & 0,4427 & Moderada \\
\hline M. lemniscatus helleri & 10 & 0,5472 & 0,1016 & 0,2994 & Moderada \\
\hline M. lemniscatus lemniscatus & 9 & 0,7748 & 0,0142 & 0,6004 & Forte \\
\hline M. spixii obscurus & 14 & 0,8725 & 0,0005 & 0,7612 & Forte \\
\hline M. spixii spixii & 15 & 0,8657 & 0,0003 & 0,7495 & Forte \\
\hline M. surinamensis & 13 & 0,9942 & 0,0000 & 0,8916 & Muito forte \\
\hline
\end{tabular}

* Correlação bem fraca (r 0,00-0,19); correlação fraca (r 0,20-0,39); correlação moderada (r 0,40-0,69); correlação forte ( $\mathrm{r}$ 0,70-0,89); correlação muito forte (r $0,90-1,00)$.

Ao analisar os resultados das regressões, observamos que a representação dos resíduos em função dos valores estimados da quantidade de veneno extraída do gráfico residual distribui-se de forma aleatória, não apresentando comportamento padronizado ao longo ou próximo da reta, implicando na não homocedasticidade dos dados, o que reforça a não significância dos resultados.

Ao relacionarmos os valores de $\mathrm{r}$ e $\mathrm{p}$ com a quantidade de amostras de veneno extraído, verificamos que, no grupo de espécies que apresentaram correlação positiva e não significativa, a quantidade de amostras de veneno utilizadas não influenciou diretamente na força da correlação: espécies que possuíam poucas amostras apresentaram alta força na correlação, como, por exemplo, $M$. averyi, com apenas três amostras (correlação forte) e $M$. decoratus, também com três amostras (correlação muito forte). De outro lado, M. altirostris, com a maior quantidade de amostras entre essas espécies, apresentou correlação bem fraca, juntamente com M. albicinctus. Três espécies (M. $l$. helleri, M. brasiliensis e M. ibiboboca) apresentaram correlação moderada com dez, oito e seis amostras de veneno respectivamente (Tabela 2).

Sete táxons apresentaram correlação positiva e significativa entre quantidade de veneno e tamanho do animal (M. corallinus, $M$. frontalis, $M$. lemniscatus carvalhoi, $M$. lemniscatus lemniscatus, $M$. spixii spixii, M. spixii obscurus, M. surinamensis). No geral, a distribuição das amostras de veneno apresentou-se de forma homogênea e padronizada, favorecendo a homocedasticidade dos dados, refletindo diretamente nos valores da variância, superiores a $32 \%$, o que pode ter influenciado na significância dos resultados. Já no grupo de espécies que apresentaram correlação positiva e significativa, a quantidade de amostras de veneno utilizadas, variando entre nove e 130, parece ter influenciado nos resultados das correlações. Neste caso, três espécies apresentaram a força da correlação moderada, três forte e uma muito forte (Tabela 2).

Foram analisadas sete amostras da espécie $M$. hemprichii, a qual apresentou correlação negativa e não significativa entre quantidade de veneno e tamanho. Além disso, apresentou semelhança ao primeiro grupo de espécies quanto à distribuição das amostras, a qual se manteve de forma aleatória e não padronizada, sugerindo a não homocedasticidade dos dados, o que reflete a não significância dos resultados. Nesse caso, a quantidade de amostras parece ter influenciado diretamente nos valores de $\mathrm{r}$ e $\mathrm{p}$ (Tabela 2).

\section{DISCUSSÃO}

A alta diversidade conhecida de cobras corais no Brasil deveria ser uma preocupação nos acidentes humanos, pois os venenos dessas serpentes possuem variações na composição das toxinas, derivadas de variabilidades populacionais e ontogenéticas e a capacidade inoculadora de veneno entre as espécies. 
Soma-se a esses fatos o pouco conhecimento da toxinologia do veneno da maioria das espécies de Micrurus do Brasil. 3,7,8

Com uma diversidade de 35 táxons de cobras corais para o Brasil, a região Norte, representada com $24(70,6 \%)$ desses táxons, seria, em tese, a mais complicada em termos dos acidentes elapídicos humanos, sendo que a região Sudeste (cinco táxons) poderia representar o oposto. No entanto, o aspecto que mais contabiliza os acidentes elapídicos é o grau de ocupação do espaço e, consequentemente, o maior potencial de contato entre humanos e animais. Dessa forma, a região Norte pode ainda se tornar um grande problema, pois a ocupação humana acontece de forma agressiva nas fronteiras sul e leste dessa região.

Para a indicação da soroterapia nos acidentes elapídicos, o Ministério da Saúde recomenda classificar como potencialmente graves todos os casos em que houver presença de sintomas. Está indicado o uso de 10 ampolas de SAE administradas por via endovenosa, em dose única. ${ }^{16}$ Isso se deve muito mais ao fato da possível gravidade de um acidente com efeitos neurotóxicos do que à realidade encontrada nos atendimentos, onde a grande maioria dos envenenamentos se manifestam com discretas alterações, sendo raros os acidentes com manifestações neuroparalíticas. , $^{3,8,18}$

Houve uma forte tendência de correlação positiva entre tamanho corporal e quantidade de veneno extraído, principalmente quando todas as espécies foram analisadas juntas, o que corrobora a premissa de que quanto maior o animal, maior a quantidade de veneno injetado e, consequentemente, maior a gravidade do acidente. ${ }^{19,20}$ Este fato também pode ser confirmado analisando as manifestações dos casos de envenenamento por $M$. surinamensis e $M$. filiformis relatados por Pardal et al. ${ }^{21}$

Segundo Naghettini e Pinto, ${ }^{22}$ é importante salientar que variáveis altamente correlacionadas não apresentam necessariamente relação de causa e efeito e, sim, a tendência de variação conjunta que algumas variáveis apresentam. Isso pôde ser observado para as sete espécies que apresentaram correlação positiva e não significativa (M. albicinctus, $M$. altirostris, $M$. lemniscatus helleri, M. ibiboboca, M. brasiliensis, $M$. averyi e $M$. decoratus). Entretanto, os mesmos autores enfatizam que evidências de relações causais podem ser obtidas a partir do conhecimento dos processos envolvidos, o que, no caso dos acidentes com Micrurus, pode estar relacionado ao tamanho corporal do animal e à gravidade do acidente. ${ }^{23}$

Um fator que pode ter influenciado na não significância da correlação, mesmo ela sendo positiva, é a ocorrência de correlações espúrias, ou seja, qualquer correlação aparente entre duas variáveis que não estejam correlacionadas de fato, devido à distribuição não equilibrada dos dados refletida claramente na distribuição das amostras..$^{22-24}$ Além disso, a ausência de significância estatística pode estar relacionada ao pequeno tamanho da amostra. Na maioria dos testes efetuados no presente estudo, as espécies que possuíam maior quantidade de amostras foram as que apresentaram as correlações positivas e estatisticamente significativas.

A análise residual pelo ajuste visual, método recomendado por diversos autores, ${ }^{22,23,25}$ para análise de correlação para a espécie $M$. hemprichii, mostrou que a distribuição das amostras foi extremamente aleatória e não homogênea, indicando que uma parcela da variação permanece não explicada e deve ser atribuída ao acaso, reforçando a não significância da correlação.

Estes resultados ilustram, na prática, as diferenças na capacidade de inoculação de veneno entre as espécies de Micrurus estudadas. Além disso, são dados obtidos por extrações manuais, o que pode resultar em um volume (e peso seco) superior ao que a serpente inocularia em um acidente. Em uma amplitude de peso seco entre $8,04 \mathrm{mg}$ (M. albicinctus) e $52,67 \mathrm{mg}$ (M. surinamensis) fica o questionamento da real necessidade da manutenção da classificação de todos os acidentes elapídicos, mesmo os com leves sintomas, como graves, requerendo administração de uma dose de 10 ampolas de SAE. Esta recomendação do Ministério da Saúde contrasta com a própria bula do SAE. Nos testes de fabricação (in vitro), cada ampola de SAE é suficiente para neutralizar $15 \mathrm{mg}$ de veneno de serpentes Micrurus no Brasil. Devido ao porte reduzido da maioria dessas serpentes, a quantidade de veneno seco capaz de ser inoculado dificilmente chegaria a 40 ou $50 \mathrm{mg}$, além da possibilidade de picadas secas ${ }^{3,8,26}$ o que significa que essa recomendação poderia ser revista para uma dose inicial de cinco ampolas (capaz de neutralizar $75 \mathrm{mg}$ de veneno). O mesmo foi sugerido por Pardal et al. ${ }^{21}$

A variabilidade na composição e o mecanismo de ação do veneno de cobras corais foi descrita inicialmente para $M$. corallinus, $M$. frontalis e M. lemniscatus, pois a maior parte dos estudos toxinológicos (pioneiros) e da produção de soros se concentrava na região Sudeste. Essas três espécies (de distribuição conhecida para essa região) sempre foram utilizadas como referência e foram incorporadas no pool de inoculação para a produção do SAE. ${ }^{6,27-29}$ Quanto a esse pool de imunização para a produção 
do SAE, em 1978 pesquisadores realizaram estudos experimentais sugerindo a possibilidade de produção de um antiveneno para as Américas, onde se verificou que o antiveneno produzido no Brasil, com venenos dessas três espécies, não era capaz de neutralizar efetivamente o veneno de $M$. altirostris, espécie abundante na região sul do país, e M. surinamensis, espécie amazônica. ${ }^{11}$ Apesar disso, o SAE continua sendo produzido com esse pool de venenos das três espécies (M. corallinus, M. frontalis e M. lemniscatus).

Esses aspectos são de importância capital para a saúde pública no Brasil, desde que a diversidade alta dessas serpentes se distribui de forma não uniforme em todo o território nacional e o SAE é produzido somente com espécies de ocorrência na região Sudeste. A combinação de dados da diversidade biológica das cobras corais no Brasil e a variabilidade toxinológica sugere a condução de estudos mais aprofundados visando uma melhor avaliação da composição do $p o o l$ imunizante e da qualidade do SAE para uso em todo o território brasileiro.

Concluindo, a relação entre quantidade de veneno extraída e comprimento corporal de 18 espécies e subespécies de Micrurus do Brasil corroboram o fato de estes serem animais de porte pequeno e médio, com baixa capacidade inoculatória, o que resulta em possíveis acidentes de menor gravidade. Além disso, a suposição de que o SAE produzido no Brasil é eficaz na neutralização cruzada de todas as espécies de Micrurus contrasta com a escassez de estudos clínicos, sugerindo novas pesquisas para sanar essas dúvidas e, se necessário, rever o pool de imunização desse soro hiperimune, que atualmente é restrito a somente três espécies.

\section{REFERÊNCIAS}

1. Bérnils RS, Costa HC (org.). Sociedade Brasileira de Herpetologia - SBH. Brazilian reptiles - List of species 2012. [Internet]. São Paulo; 2013. [cited 2013 May 15]. Available from: http://www/sbherpetologia.org.br/

2. Silva Junior NJ, Bucaretchi F. Mecanismos de ação do veneno elapídico e aspectos clínicos de acidentes. In: Cardoso JLC, França FOS, Wen FH, Málaque CMS, Haddad Junior V. Animais Peçonhentos no Brasil - Biologia, Clínica e Terapêutica dos Acidentes. 1ํㅡㄹ. ed. São Paulo: Sarvier; 2003. p. 99-107.

3. Silva Junior NJ, Bucaretchi F. 2009. Mecanismos de ação do veneno elapídico e aspectos clínicos dos acidentes. In: Cardoso JLC, França FOS, Wen FH, Málaque CMS, Haddad Junior V. Animais Peçonhentos no Brasil - Biologia, Clínica e Terapêutica dos Acidentes. $2^{\mathrm{a}}$ ed. São Paulo: Sarvier; 2009. p. 116-24.

4. Pires MG, Silva Jr NJ, Feitosa DT, Prudente ALC, Filho GAP, Zaher H. A new species of triadal coral snake of the genus Micrurus Wagler, 1824 (Serpentes: Elapidae) from northeastern Brazil. Zootaxa. 2014;(4):569-84.

5. Vital Brazil O, Fontana MD. Ações pré-juncionais e pós-juncionais da peçonha da cobra coral Micrurus corallinus na junção neuromuscular. Memórias do Instituto Butantan. 1984;(40/41):221-40.

6. Gutierrez JM, Rojas G, Silva Junior NJ, Nunes J. Experimental myonecrosis induced by the venoms of South American Micrurus (coral snakes). Toxicon. 1992;30(10):1299-302.

7. Tan NH, Ponnudurai G. The biological properties of venoms of some american coral snakes (Genus Micrurus). Comp Biochem Physiol B Biochem Mol Biol. 1992;101(3):471-4.

8. Silva Junior NJ, Aird SD. Prey specificity, comparative lethality and compositional differences of Brazilian coral snake venoms. Comp Biochem Physiol C Toxicol Pharmacol. 2001;128C(3):425-56.

9. Serapicos EO, Merusse JLB. Análise comparativa entre tipos de alimentação de Micrurus corallinus (Serpentes, Elapidae) em cativeiro. Iheringia, Sér. Zool. 2002;92(4):99-103.

10. Zatti CA, Ascari RA. Acidentes por Animais Peçonhentos no Brasil no Período de 2009 a 2012. Braz J Surg Clin Res. 2013;3(1):16-20.

11. Bolaños R, Cerdas L, Abalos JW. Venenos de lãs serpientes coral (Micrurus spp.): informe sobre um antiveneno polivalente para las americas. Bol Sanit Panam. 1978;84(2):128-33.

12. Tanaka GD, Furtado MFD, Portaro FCV, Sant'anna AO, Tambourgi DV. Diversity of Micrurus snake species related to their venom toxic effects and the prospective of antivenom neutralization. PLoS Negl Trop Dis. 2010;4(3):e622.

13. Pessoa AM. Aspectos Biológicos na Avaliação dos Acidentes Causados por Cobras Corais no Brasil. [Dissertação]. [Goiânia]: Pontifícia Universidade Católica de Goiás; 2012. 60p.

14. Roze JA. Coral Snakes of the Americas: Biology, Identification, and Venoms. Krieger publishing company: Malabar, Florida; 1996. 328p.

15. Campbell JA, Lamar WW. The venomous reptiles of western hemisphere. Ithaca and London: Cornell University Press; 2004.

16. SINAN. Sistema de Informação de Agravo de Notificação. Acidentes por animais peçonhentos. Brasil; 2013 [cited 2013 Jul 11]. Available from: http://dtr2004.saude.gov.br/sinanweb/index.php

17. Brasil. Ministério da Saúde. Manual de Diagnóstico e Tratamento de Acidentes por animais peçonhentos. Ministério da Saúde: Brasília, DF; 2001. 
18. Bucaretchi F, Hyslop S, Vieira RJ, Toledo AS, Madureira PR, De Capitani EM. Bites by coral snakes (Micrurus spp.) in Campinas, state of São Paulo, southeastern Brazil. Rev Inst Med Trop São Paulo. 2006;48(3):141-5.

19. Manock SR, Suarez G, Graham D, Avila-Aguero ML, WarrelL DA. Neurotoxic envenoming by South American coral snake (Micrurus lemniscatus helleri): case report from eastern Ecuador and review. Trans R Soc Trop Med Hyg. 2008;102(11):1127-32.

20. Warrell DA. Epidemiology, clinical features and management of snake bites in Central America. In: Campbell JA, Lamar WW (Eds.). The Venomous Reptiles of Western Hemisphere. Ithaca: Comstock Pub. Associates; 2004. 2 vol. p. 709-761.

21. Pardal PPO, Pardal JSO, Gadelha MAC, Rodrigues LS, Feitosa DT, Prudente ALC, Wen FH. Envenomation by Micrurus coralsnakes in the Brazilian Amazon region: report of two cases. Rev Inst Med Trop São Paulo. 2010;52(6):333-7.

22. Naghettini M, Pinto EJA. Correlação e Regressão. In: Naghettini M, Pinto EJA. Hidrologia Estatística. Belo Horizonte, MG: Editora do Serviço Geológico do Brasil - CPRM; 2007. p. 354-400.

23. Bussab WO, Morettin PA. Estatística básica. 5ำ ed. São Paulo: Saraiva; 2006.

24. Matos MA. Manual Operacional para a Regressão Linear. Portugal: Faculdade de Engenharia da Universidade do Porto; 1995.

25. Magnusson WE, Mourão G. Estatística sem Matemática: A Ligação entre as Questões e a Análise. Londrina: Editora Planta; 2003.

26. Silva Junior NJ. Micrurus. In: Nicolella A, Barros E, Torres JB, Marques MG (Org.). Acidentes com Animais Peçonhentos. 1a ed. Porto Alegre: Ministério da Saúde; 1997. p. 104-10.

27. Vital Brazil O. Coral snake venoms: mode of action and pathophysiology of experimental envenomation. Rev Inst Med Trop São Paulo. 1987;29:119-26.

28. Vital Brazil O, Vieira RJ. Neostigmine in the treatment of snake accidents caused by Micrurus frontalis: report of two cases. Rev Inst Med Trop São Paulo. 1996;38:61-7.

29. Cardoso DF, Yamaguchi IK, Silva AMM. Produção de soros antitoxinas e perspectivas de modernização por técnicas de biologia molecular. In: Cardoso JLC, França FOS, Wen FH, Málaque CMS, Haddad Jr V. Animais Peçonhentos no Brasil - Biologia, Clínica e Terapêutica dos Acidentes. $2^{\mathrm{a}}$ ed. São Paulo: Sarvier; 2009. p. 419-31. 